\title{
Effect of Catalyst Type on the Properties of Biodiesel from Jathropha and Moringa Oil Blend
}

\author{
Isaac A. Bamgboye ${ }^{1}$ (D), Blessing N. Iyidiobu 1,* (D) \\ 1 Department of Agricultural and Environmental Engineering, University of Ibadan, Ibadan, Oyo State, Nigeria. \\ 2 Department of Agricultural and Environmental Engineering, Federal University of Agriculture, PMB 2373, Makurdi, Benue \\ State, Nigeria. \\ *Corresponding author Email: zikalike2@gmail.com \\ DOI: https://doi.org/10.34256/irjmt2146 \\ Received: 07-05-2021, Revised: 12-05-2021, Accepted: 12-05-2021, Published: 05-07-2021
}

\begin{abstract}
Various methods of biodiesel production have been developed in the recent past to reduce production costs. These new approaches may have varying effects on ester quality. Thus an investigation is necessary to determine cost saving measures that do not compromise ester quality. This work examined the effects of a cost saving strategy on Biodiesel quality. This conservative method involved the transesterification of a JathrophaMoringa oil blend using a blend of two primary alcohols. Three alkaline catalysts were also used. The reaction conditions were: Jathropha to Moringa oil blending ratio of $4: 1$; Methanol to ethanol blending ratio of 4:1; Alkaline catalyst concentration of $0.5 \mathrm{w} / \mathrm{w} \%$; reaction time of 40 minutes; stirring speed of $1000 \mathrm{rpm}$; Temperature of $60^{\circ} \mathrm{C}$ and an Alcohol to oil molar ratio of 7.5. Biodiesel samples were tested according to ASTM D6751 and AOCS guidelines. Results indicated that the density, iodine values, flash point and fire points of esters did not vary significantly as the experiment was repeated using three different alkaline catalysts. It also showed that the effect of $\mathrm{NaOH}, \mathrm{KOH}$ and $\mathrm{CaO}$ were not always negative when they were significant. Lastly, the methods applied in this did not compromise ester quality with regard to observed fuel parameters.
\end{abstract}

Keywords: Cost, Biodiesel, Blending, Quality, Jatropha, Moringa

\section{Introduction}

Population growth and increasing industrialization have driven man's insatiable thirst for energy as a result of depleting fossil fuel reserves and the environmentally polluting nature of the fuels. One promising alternative to fossil fuel is biodiesel. However it remains less attractive than petroleum diesel because of high production costs. The use of various alternative methods and raw materials to save biodiesel production costs have been investigated but a full understanding of impacts of some of these methods on fuel quality is not yet established.

Attempts at cutting production costs include the use of poor quality feedstock such as Jathropha [1] and Loofah [2]. However, the use of high FFA oil feedstock like Jathropha can compromise ester yield in a onestage transesterification process [3]. Blending of oil feedstock has also been experimented. Ref. [4] reported that the fuel quality of alkyl-esters, in terms of oxidation stability, density and kinematic viscosity were markedly improved by trans-esterification of binary blends of castor-cotton oil, castor-soybean oil and castor canola-canola oil using methanolysis, at $25^{\circ} \mathrm{C}$ for 40 minutes and ethanolysis, at $60^{\circ} \mathrm{C}$ for 5 minutes. Ref. [5] achieved a methyl-ester conversion beyond $98 \%$ by transesterifing a blend of palm and rubber seed oils using $\mathrm{KOH}$ catalyst at $55^{\circ} \mathrm{C}$ for 5 hours. Thus feedstock combination of Jathropha and Moringa oils may improve the quality of resulting oil feedstock blend in a fashion that saves production costs without comprising yield.

Other attempts to improve the renewability of biodiesel include the use of ethanol. The use of ethanol in biodiesel production is very challenging. The problems of very long reaction time and high temperature requirements have caused much discouragement [6]. However, the partial addition of ethanol to methanol can decrease the reaction time and the renewability of the final product. Ref. [7] reported that an optimal methanol/ethanol blend, in ratio of $80: 20$---for the trans-esterification of babassu oil using $1.5 \% \mathrm{KOH}$ catalyst, 1:4.6 oil/alcohol ratio, stirring speed of $1700 \mathrm{rmp}$, for 30 minutes at room 
temperature-resulted in an alkyl-ester yield of $95.32 \%$ with a high ester content of $98.70 \%$.

The foremost contribution to biodiesel production costs is the use of alkaline catalysts [8]. Hence catalysts used for biodiesel production in a single plant may have to be changed to adapt to market realities. The effects of these catalysts on biodiesel diesel quality is important because information on the properties of fuels produced through their varied use and the application of other novel cost saving processes will be useful to their effective commercialization $[8,9]$.

This work investigated the effects of three alkaline catalysts on the quality of alkyl-esters. It also determined the properties of esters produced by transesterification of Jathropha and Moringa oil feedstock blend using a mixture of two alcohols in comparison to ASTM D6751 and petrodiesel standards.

\section{Methodology}

\subsection{Reagents and Apparatus}

Jathropha and Moringa seeds were bought from local farmers in Dekina and Makurdi local government areas of Kogi and Benue states. The seeds were then decorticated by removing the hulls and shell and were heated to $70^{\circ} \mathrm{C}$ for 5 minutes in order to extract their oil content using an oil expeller. The oil collected was kept in the laboratory to undergo natural degumming for a week. Methanol, ethanol, $\mathrm{NaOH}, \mathrm{KOH}, \mathrm{CaO}$ and ethyl ether of high purity were procured from chemical stores in Ibadan, Oyo state. A small reactor designed to transesterify small amounts of oil was used for this study. Separating funnels, measuring cylinders, wash bottles, specimen bottles and basic apparatus for qualitative and quantitative analysis were acquired.

\subsection{Experimental Design and Analysis}

The study was arranged as a completely randomised, one factor, 3 levels Design for each of 8 dependent variables with 3 replications amounting to 72 runs of experiment at 9 runs per dependent variable. Data collected was analysed using a One-way ANOVA in which ANOVA models were used to compare the mean response values at different levels of the single factor (Catalyst type). Each level of this factor - $\mathrm{NaOH}$, $\mathrm{KOH}$, and $\mathrm{CaO}$ - was investigated to see if the response with regard to an oil property was significantly different from the response at other levels of the factor for the same oil quality. Duncan Mean separation was used to determine the source of differences where they are significant. SPSS 20 statistical software was used for this analysis.

\subsection{Reaction Condition}

The three catalysts were studied under similar processing condition. The transesterification conditions were: Jathropha to Moringa blending ratio of $4: 1$, Methanol to ethanol blending ratio of $4: 1$, Concentration of $0.5 \mathrm{w} / \mathrm{w} \%$ of oil blend, Mix speed of $1000 \mathrm{rpm}$, Temperature of $60^{\circ} \mathrm{C}$ and an Alcohol to oil molar ratio of 7.5. Every reaction was replicated 3 times for each catalyst. A working weight of $20 \mathrm{~g}$ and a 45 minute reaction time was used for these reactions.

Esters were separated, washed and stored in sample bottles at the end of each reaction. These were then characterized for various fuel properties using test standards recommended by ASTM D6751 and AOCS methods [10,11]. A summary of these methods are presented in table 1.

Table 1. A summary of Characterisation methods employed

\begin{tabular}{|l|l|l|l|}
\hline Property & Method & Limits & Units \\
\hline Flashpoint & D 93 & $130 \mathrm{~min}$ & ${ }^{\circ} \mathrm{C}$ \\
\hline Acid number & D 664 & $0.80 \mathrm{max}$ & $\mathrm{Mg} \mathrm{KOH} / \mathrm{g}$ \\
\hline $\begin{array}{l}\text { Kinematic viscosity, } \\
40{ }^{\circ} \mathrm{C}\end{array}$ & D 445 & $1.9-6.0$ & $\mathrm{~mm}^{2} / \mathrm{s}$ \\
\hline Cloud point & D 2500 & -3.0 to 12 & ${ }^{\circ} \mathrm{C}$ \\
\hline Pour point & D 97 & -15 to 16 & ${ }^{\circ} \mathrm{C}$ \\
\hline Fire point & D 93 & $\mathrm{Nd}$ & ${ }^{\circ} \mathrm{C}$ \\
\hline lodine value & & & \\
\hline Saponification value & & & \\
\hline Density & D 5002 & $860-900$ & $\mathrm{~kg} / \mathrm{m}^{3}$ \\
\hline Specific gravity & D 287 & 0.88 & $\mathrm{~g} / \mathrm{cm}^{\circ}$ \\
\hline
\end{tabular}

Sources: ASTM D6751 [12, 13, 14]

\section{Results and Discussion}

\subsection{Iodine Value}

As shown in Tables 2 and 4, the alkyl-ester sample produced using calcium oxide catalyst had the highest iodine value (80.00), while the alkyl-ester sample produced using sodium hydroxide had the least iodine value (73.00). Nevertheless, all the three values were still within the allowable range prescribed by AOCS. Furthermore, the values were also within the limits required for grade 1 petrol diesel. Table 3 showed that iodine value did not vary significantly among the three catalyst as determined from esters samples they produced. This meant that variations in catalyst type did 
Vol 3 Iss 4 Year 2021 Isaac A. Bamgboye \&Blessing N. Iyidiobu /2021

not greatly affect fuel iodine value. This similarity resulted from the use of the same oil feedstock blend
(80\% Jathropha oil and $20 \%$ Moringa oil) in the preparation of all three ester samples [15].

Table 2. Characterisation and Comparison with Standards for the three Biodiesel samples produced at optimal conditions

\begin{tabular}{llllll}
\hline Property & I (CaO) & II $(\mathrm{KOH})$ & III $(\mathrm{NaOH})$ & ASTM D 6751 & ASTM D975 \\
\hline $\mathrm{K}\left(\mathrm{mm}^{2} / \mathrm{s}\right)$ & 5.33 & 4.76 & 4.10 & $1.9-6.0$ & $1.3-4.1$ \\
Flashpoint $\left({ }^{\circ} \mathrm{C}\right)$ & 186 & 185 & 182 & $130 \mathrm{~min}$ & $60-80$ \\
Firepoint $\left({ }^{\circ} \mathrm{C}\right)$ & 200 & 196 & 193 & $\mathrm{nd}$ & $\mathrm{Nd}$ \\
Pourpoint $\left({ }^{\circ} \mathrm{C}\right)$ & -2.1 & -1.8 & -0.9 & -15 to 16 & -35 to +15 \\
Cloudpoint $\left({ }^{\circ} \mathrm{C}\right)$ & 1.5 & 2.1 & 2.8 & -3.0 to 12 & -15 to +5 \\
$\mathrm{~A}(\mathrm{mgKOH} / \mathrm{g})$ & 1.695 & 0.414 & 0.121 & $0.80 \mathrm{max}$ & \\
$\mathrm{D}\left(\mathrm{Kg} / \mathrm{m}^{3}\right)$ & 871 & 881 & 875 & $860-900$ & 850 \\
lodine number & 80 & 78 & 73 & $120 \mathrm{max}$ & \\
\hline
\end{tabular}

$\mathrm{K}=$ Kinematic viscosity at $40^{\circ} \mathrm{C} ; \mathrm{A}=\mathrm{Acid}$ number; $\mathrm{D}=$ Density. Note: I, II, and III are alkyl-ester samples produced using $\mathrm{CaO}, \mathrm{KOH}$ and $\mathrm{NaOH}$ respectively. ASTM D6751 ASTM D975 are standards for biodiesel and grade1 Petrodiesel respectively

Table 3. ANOVA for the Effects of catalyst type on Alkyl-ester quality

\begin{tabular}{cccccc}
\hline Property & SS & Df & M S & F & Sig. \\
\hline KV & 2.273 & 2 & 1.137 & 22.780 & $0.002^{*}$ \\
Flashpoint & 26.000 & 2 & 13.000 & 2.600 & $0.154^{\text {NS }}$ \\
Firepoint & 74.000 & 2 & 37.000 & 0.665 & $0.549^{\mathrm{NS}}$ \\
Pour point & 2.340 & 2 & 1.170 & 22.558 & $0.002^{*}$ \\
Cloud Point & 2.540 & 2 & 1.270 & 14.111 & $0.005^{*}$ \\
Density & 152.000 & 2 & 76.000 & 1.226 & $0.358^{\mathrm{NS}}$ \\
Acid Value & 4.204 & 2 & 2.102 & 616.524 & $0.000^{*}$ \\
lodine Value & 78.000 & 2 & 39.000 & 2.294 & $0.182^{\mathrm{NS}}$
\end{tabular}

$\mathrm{KV}=$ Kinematic Viscousity; $\mathrm{SS}=\mathrm{Sum}$ of squares; $\mathrm{MS}=$ Mean squares $\mathrm{NS}=$ Not significant at $\mathrm{p}>0.05$ and ${ }^{*}$ $=$ significant at $p<0.05$

Table 4. Effects of catalyst type on Alkyl-ester quality

\begin{tabular}{|c|c|c|c|c|c|c|c|c|}
\hline $\begin{array}{l}\text { Catalyst } \\
\text { type }\end{array}$ & $\begin{array}{l}\mathrm{K} \\
\left(\mathrm{mm}^{2} / \mathrm{s}\right)\end{array}$ & $\begin{array}{l}\text { Flashpoint } \\
\left({ }^{\circ} \mathrm{C}\right)\end{array}$ & $\begin{array}{l}\text { Fire point } \\
\left({ }^{\circ} \mathrm{C}\right)\end{array}$ & $\begin{array}{l}\text { Pourpoint } \\
\left({ }^{\circ} \mathrm{C}\right)\end{array}$ & $\begin{array}{l}\text { Cloudpoint } \\
\left({ }^{\circ} \mathrm{C}\right)\end{array}$ & $\begin{array}{l}\text { Acid value } \\
(\mathrm{mgKOH} / \mathrm{g})\end{array}$ & $\begin{array}{l}\text { lodine } \\
\text { value }\end{array}$ & $\begin{array}{l}\text { Density } \\
\left(\mathrm{Kg} / \mathrm{m}^{3}\right)\end{array}$ \\
\hline \multirow{2}{*}{$\mathrm{CaO}$} & $5.330^{c}$ & $186.000^{a}$ & $200.000^{a}$ & $-2.100^{a}$ & $1.500^{\mathrm{a}}$ & $1.695^{c}$ & $80.000^{a}$ & $871.000^{a}$ \\
\hline & $(0.02646)$ & (3.60555) & $(9.16515)$ & $(0.18520)$ & $(0.36056)$ & $(0.022913)$ & $(4.58258)$ & $(8.71780)$ \\
\hline \multirow{2}{*}{$\mathrm{KOH}$} & $4.760^{b}$ & $185.000^{a}$ & $196.000^{a}$ & $-1.800^{a}$ & $2.100^{\mathrm{b}}$ & $0.414^{b}$ & $78.000^{a}$ & $881.000^{a}$ \\
\hline & $(0.02646)$ & $(1.000)$ & $(7.21110)$ & $(0.28513)$ & $(0.10000)$ & $(.097755)$ & $(4.58258)$ & 8.18535 \\
\hline \multirow{2}{*}{$\mathrm{NaOH}$} & $4.100^{a}$ & $182.000^{a}$ & $193.000^{a}$ & $-0.900^{b}$ & $2.800^{c}$ & $0.121^{a}$ & $73.000^{a}$ & $875.000^{a}$ \\
\hline & $(0.38510)$ & $(1.000)$ & $(5.56776)$ & $(0.20000)$ & $(0.36056)$ & $(0.012166)$ & $(3.00000)$ & $(6.55744)$ \\
\hline
\end{tabular}

$\mathrm{K}=$ Kinematic viscosity at $40^{\circ} \mathrm{C}$; Values with similar superscripts within the same column are not significantly different. Values enclosed in parenthesis are standard deviations 
Ref. [15] reported an iodine value of 141.9 for sunflower ethyl-ester which was higher than iodine values obtained in this study. The generally high iodine value in the current study indicated that the parent oil feedstock blend had a high degree of unsaturation [16].

\subsection{Density}

Tables 2 and 4 showed that esters of higher density could be produced using potassium hydroxide catalyst as compared to those produced using $\mathrm{NaOH}$ and $\mathrm{CaO}$ catalysts. Nevertheless, all the three values (881, 875 and $871 \mathrm{~kg} / \mathrm{m}^{3}$ for $\mathrm{KOH}, \mathrm{NaOH}$ and $\mathrm{CaO}$ respectively) were within the allowable range prescribed by ASTM D6751. Table 3 showed that density did not vary significantly among the three catalyst as determined from esters samples they produced. This meant that variations in catalyst type did not greatly affect fuel density. Ref. [6] reported a density of $880 \mathrm{~kg} / \mathrm{m}^{3}$ for Canola oil methyl-ethyl-esters produced from the partial ethanolysis of canola oil with a Methanol/ethanol blending ratio of $4.5: 1.5$. This density value fell within range of those observed in this study. Negligible variations in density values for all the three biodiesel samples had resulted from the use of oil-feedstock of varying alcohol blending ratios with a significant degree of unsaturation [16]. However, unsaturation in the parent oil did not lead to alkyl-ester densities that were so high that they exceeded standards [17]. Increasing ester density can lead to poor fuel atomization on one hand and high energy content on the other. These factors compete to either improve or weaken engine performance [17].

\subsection{Acid Value}

Tables 2 and 4 showed that the alkyl-ester produced using calcium oxide catalyst had the highest acid value of 1.695 , while the alkyl-ester produced using sodium hydroxide had the least value of 0.121 .

Acid value for all the three samples did not meet the ASTM standard for biodiesel and grade 1 petro diesel. However, Table 3 showed that acid value varied significantly among the three catalyst as determined from esters samples produced. This indicated that variations in catalyst type greatly affected fuel acid value.

As shown in table 4 , the mean acid values were $0.414,0.1214$ and $1.695 \mathrm{mgKOH} / \mathrm{g}$ for $\mathrm{KOH}$, $\mathrm{NaOH}$ and $\mathrm{CaO}$ respectively. These values did not compare with what was reported by Ref. [6] that observed an acid value of 0.7 for Canola oil methylethyl-esters produced from the partial ethanolysis of canola oil with a Methanol-ethanol blending ratio of 3:3. The variation may be due to the type of oil used and the methanol-ethanol ratio.

\subsection{Kinematic Viscosity}

The kinematic viscosity as shown in Tables 2 and 4 was $4.10 \mathrm{~mm}^{2} / \mathrm{s}, 4.76 \mathrm{~mm}^{2} / \mathrm{s}$ and $5.33 \mathrm{~mm}^{2} / \mathrm{s}$ for esters produced using $\mathrm{NaOH}, \mathrm{KOH}$ and $\mathrm{CaO}$ catalysts. These values met the ASTM D6751 standards. However, ASTM D975 for grade 1 petrodiesel was not satisfied by the ester produced using $\mathrm{CaO}$. The viscosities were all lower than 7.10 to 43.4 $\mathrm{mm}^{2} / \mathrm{s}$ obtained from different blends of loofa oil [2].

However, from Table 3, kinematic viscosity varied significantly among the three catalyst from the esters produced. This shows that the kinematic viscosity of biodiesel produced will vary considerably with variation in the alkaline catalyst used. This knowledge is important because high viscosity may cause atomization problems and formation of deposits in the combustion chamber of combustion ignition engines, thereby affecting the performance of the engine [18].

\subsection{Flash point}

As showed in Tables 2 and 4, the flash points of the three esters produced with sodium hydroxide, potassium hydroxide and calcium oxide catalysts were $182{ }^{\circ} \mathrm{C}, 185{ }^{\circ} \mathrm{C}$ and $186{ }^{\circ} \mathrm{C}$ respectively. The flash points did not vary significantly among the three catalyst as determined from the esters produced as shown in Table 3. This meant that altering the alkaline catalyst used for transesterification did not greatly affect the flash point of fuel.

These values of the flashpoint were within the ASTM D6751 and D975 standards values for biodiesel and petro diesel respectively. The values were however higher than 74 to $86{ }^{\circ} \mathrm{C}$ obtained from blends of loofa oil [2]. The higher flash point is an indication that the fuel is safe for storage and transportation without fear of fire outbreak.

However, a better flashpoint value of $210^{\circ} \mathrm{C}$ for groundnut oil ethyl ester was obtained by Oniya and Bamgboye [19]. This slight variation from values in the present study resulted from the different process conditions and oil feedstock.

\subsection{Fire Point}

The fire point as depicted in Tables 2 and 4 were $193^{\circ} \mathrm{C}, 196{ }^{\circ} \mathrm{C}$ and $200{ }^{\circ} \mathrm{C}$ for sodium hydroxide, 


\section{Vol 3 Iss 4 Year 2021 Isaac A. Bamgboye \&Blessing N. Iyidiobu /2021}

potassium hydroxide and calcium oxide catalysed esters. These fire point values met flash point standards for biodiesel and petro diesel respectively. However, the fire points did not vary significantly among the three catalyst as determined from esters produced (Table 3). This meant that altering the alkaline catalyst used for transesterification did not greatly affect the fire point of fuel.

The fire point of a fuel is the lowest temperature above the flashpoint at which the vapour of that fuel will cause sustained combustion. Therefore, esters with fire points significantly higher than their flash points and fire point standards may not attain sustained combustion in the event of an accidental explosion. This gurantees safety during storage and transport. . Furthermore a fire point value of $196{ }^{\circ} \mathrm{C}$ for Rice bran oil methyl ester was obtained by Ref. [20].This same value was recorded for esters produced in the current work using $\mathrm{KOH}$ catalysts. This parity followed from the partially similar reaction conditions reported by Ref. [20] for Rice bran oil methyl ester: use of hydroxide catalysts at a concentration of $0.5 \mathrm{w} / \mathrm{w} \%$ of oil at approximately $60{ }^{\circ} \mathrm{C}$ as in the current work.

\subsection{Pour Point}

As seen in Tables 2 and 4 , the pour points for esters produced with sodium hydroxide, potassium hydroxide and calcium oxide catalysts were -0.9, -1.8 and -2.1 respectively. An acceptable pour point value for all locations is difficult to set as it depends on weather conditions which vary from place to place. The climatic classification puts the minimum temperature for tropics at $18{ }^{\circ} \mathrm{C}$ or higher [21]. Hence the biodiesel samples in this study were compatible with tropical environment since their pour point values were still below the lowest tropical temperature.

The pour point varied significantly among the three catalyst as shown in Tables 3 and 4 . This indicated that variations in catalyst type greatly affected the pour point of fuel. The result from $\mathrm{CaO}$ and $\mathrm{KOH}$ catalysts shows that they may be used interchangeably. However, if significant variations in pour point of biodiesel produced were not important, $\mathrm{NaOH}$ can be used instead of $\mathrm{CaO}$ and $\mathrm{KOH}$ catalysts. The pour points of the esters in this study was high in comparison with the biodiesel and petro-diesel standards in table 2. However, lower values were initially expected because biodiesel fuels derived from fats or oils with low amounts of saturated fatty compounds as in the oil blend used for this study, usually display low Pour points [16, 22]. Ref. [24] reported a pour point of -9 for esters produced by alkaline catalysed transesterification of waste cooking oil. This figure was lower than that of the present study. The difference in pour point was caused by choice of oil feedstock [16].

\subsection{Cloud Point}

As shown in Tables 2 and 4, the cloud points for esters samples produced with sodium hydroxide, potassium hydroxide and calcium oxide catalysts were 2.8, 2.1 and 1.5 respectively. These values were lower than the standard values. This can be attributed to the fact that biodiesel derived from fats or oil with low amounts of saturated fatty compounds usually have low cloud points [22]. A universal cloud point is also difficult to specify because of varying weather conditions as one changes location [23]. Cloud point values obtained in this study were within the ASTM and petrol-diesel threshold ranges of -3 to 12 and -5 to 15 . Hence the two standards had been met. However, there was significant variation in the cloud point among the three catalyst used for esters as in Tables 3 and 4 . This indicated that variations in catalyst type greatly affected the cloud point of fuels.

Ref. [24] reported a cloud point of -2 for esters produced by alkaline catalysed transesterification of waste cooking oil, which was lower than what was obtained in this study. The difference in pour point was caused by choice of oil feedstock [16].

\section{Conclusion}

The properties of the biodiesel produced from the three different catalysts have been determined, meeting all the required standards values. The three alkaline catalysts examined in this study $(\mathrm{NaOH}, \mathrm{KOH}$ and $\mathrm{CaO}$ catalysts) can be used interchangeably if density, iodine value, flashpoint and fire point are the only parameters to be considered for ester quality assessment. Density, iodine value, flashpoint and fire point did not vary significantly among the three catalyst as determined from esters samples produced. This meant that variations in catalyst type did not greatly affect these parameters.

The blending methods employed did not compromise ester quality with regards to observed quality parameters. The effects of $\mathrm{NaOH}, \mathrm{KOH}$ and $\mathrm{CaO}$ catalysts on the quality of alkyl-esters produced were not negative even when significant at $p=0.05$.

\section{References}

[1] H.J. Berchmans, S. Hirata, Biodiesel production from crude Jatropha curcas L. seed oil with a high 
content of free fatty acids, Bioresource technology, 99 (2008) 1716-1721. [DOI]

[2] A.I. Bamgboye, O.O. Oniya, Fuel Properties of Loofah (Luffa Cylindrica L.) Biofuel Blended with Diesel, African Journal of Environmental Science and Technology, 6 (2012) 346-352. [DOI]

[3] V.J. Gerpen, B. Shanks, R. Pruszko, D. Clements, G. Knothe, Biodiesel Production Technology, National Renewable Energy Laboratory, Colorado, (2004) 37-47.

[4] M.C.G. Albuquerque, Y.L. Machado, A.E.B. Torres, D.C.S. Azevedo, C.L. Cavalcante, L. R. Firmiano, E.J.S. Parente, Properties of Biodiesel Oils Formulated Using Different Biomass Sources and Their Blends, Renewable Energy, 34 (2009) 857-859. [DOI]

[5] S. Yusup, M.A. Khan, Base Catalyzed Transesterification of Acid Treated Vegetable Oil Blend for Biodiesel Production, Biomass and Bioenergy, 34 (2010) 1500-1504. [DOl]

[6] M.G. Kulkarni, A.K. Dalai, N.N. Bakhshi, Transesterification of Canola Oil in Mixed Methanol/Ethanol System and Use of Esters as Lubricity Additive, Bioresource Technology, 98, (2007) 2027-2033. [DOI]

[7] F.C. Silva, K.S.B. Cavalcante, H.C. Louzeiro, K.R. M. Moura, A.P Maciel, L.E.B. Soledade, A.G. Souza, Production of Biodiesel from Babassu Oil Using Methanol-Ethanol Blends, Eclética Química, 35 (2010) 47-54. [DOI]

[8] C. Ofori-Boateng, E.M. Kwofie, M.Y. Mensah, Comparative Analysis of the Effect of Different Alkaline Catalysts on Biodiesel Yield, World Applied Sciences Journal, 16 (2012) 1445-1449.

[9] L. Schumacher, A. Chellappa, W. Wetherell, M.D. Russell, The Physical and Chemical Characterization of Biodiesel Low Sulfur Diesel Fuel Blends, The National Biodiesel Board University of Missouri, 85 (1995).

[10] ASTM D 5555 - 95(2017), American Standards for Testing and Measurement, https://www.astm.org/Standards /D5555.htm 2017, 2017

[11] AOAC -2005, Official Methods of Analysis, 18 ${ }^{\text {th }}$. ed. Association of Official Analytical Chemists, Arlington, V. A , 2005

[12] V.J. Gerpen, B. Shanks, R. Pruszko, D. Clements, G. Knothe, Biodiesel Analytical Methods: August 2002--January 2004, National Renewable Energy Laboratory, Colorado, (2004b) 37-47.
[13] M. Tariq, S. Ali, F. Ahmad, M. Ahmad, M. Zafar, N. Khalid, M.A. Khan, Identification, FT-IR, NMR (1 H and $13 \mathrm{C}$ ) and GC/MS Studies of Fatty Acid Methyl Esters in Biodiesel from Rocket Seed Oil, Fuel Processing Technology, 92 (2011) 336341.

[14] S.K. Hoekman, A. Broch, C. Robbins, E. Ceniceros, M. Natarajan, Review of Biodiesel Composition, Properties, and Specifications, Renewable and Sustainable Energy Reviews, 16 (2012) 143-169. [DOI]

[15] X. Lang, A. K. Dalai, N. N. Bakhshi, M. J. Reaney, P. B. Hertz, Preparation and Characterization of Bio-Diesels from Various Bio-Oils, Bioresource Technology, 80 (2001) 53-62. [DOI]

[16] E. Akbar, Z. Yaakob, S. K. Kamarudin, M. Ismail, J. Salimon, Characteristic and Composition of Jathropha Curcas Oil Seed from Malaysia and Its Potential as Biodiesel Feedstock, European Journal of Scientific Research, 29 (2009) 396-403.

[17] M. Canakci, H. Sanli, Biodiesel Production from Various Feedstock and their Effects on the Fuel Properties, Journal of Industrial Microbiology and Biotechnology, 35 (2008) 431-441 [DOI]

[18] G. Knothe, J. Krahl, J. Van-Gerpen, The Biodiesel Handbook 2nd Edition, Urbana, United States of America. AOCS press, (2015)

[19] O.O. Oniya, A.I. Bamgboye, Production of Biodiesel from Groundnut (Arachis Hypogea, L.) Oil, Agricultural Engineering International: CIGR Journal, 16 (2014) 143-150.

[20] S. Sinha, A.K. Agarwal, S. Garg, Biodiesel Development from Rice Bran Oil: Transesterification Process Optimization and Fuel Characterization, Energy Conversion and Management, 49 (2008) 1248-1257. [DOl]

[21] H. Chen, D. Chen, Koppen Climate Classification. A diagnostic Tool to Quantify Climate Variation and Change, www.http://hanschen.org/koppen/\#co ntact, 2017

[22] G. Knothe, Dependence of Biodiesel Fuel Properties on the Structure of Fatty Acid Alkyl Esters. Fuel Processing Technology, 86 (2005) 1059-1070. [DOI]

[23] U. Rashid, F. Anwar, Production of Biodiesel through Optimized Alkaline-Catalyzed Transesterification of Rapeseed Oil, Fuel, 87 (2008) 265-273. [DOI]

[24] M.N. Younis, M.S. Saeed, S. Khan, M.U. Furqan, R.U. Khan, M. Saleem, Production and 
Characterization of Biodiesel from Waste and Vegetable Oils, Journal of Quality and Technology Management, 50 (2009) 111-121.

\section{Acknowledgments}

This work has had support from the Federal University of Agriculture, Makurdi and the University of Ibadan where the laboratory experiments were carried out. Credits also go to Mr Blessing lyidiobu for his diligence and creativity in carrying out suggestions I have provided for this work. The attendants at Department of Pharmaceutical Chemistry laboratory are also acknowledged for their assistance in improving the precision of measurements made in this work.

\section{Funding}

No funding was received for conducting this study.

\section{Conflict of interest}

The authors have no conflicts of interest to declare that they are relevant to the content of this article.

\section{About the License}

(C) The author(s) 2021. The text of this article is open access and licensed under a Creative Commons Attribution 4.0 International License 